\title{
Erratum to: Modern Porous Polymer Implants: Synthesis, Properties, and Application
}

\author{
R. S. Kovylin ${ }^{a, *}$, D. Ya. Aleynik ${ }^{b}$, and I. L. Fedushkin ${ }^{a}$ \\ ${ }^{a}$ G.A. Razuvaev Institute of Organometallic Chemistry, Russian Academy of Sciences, \\ Nizhny Novgorod, 603950 Russia \\ ${ }^{b}$ Privolzhsky Research Medical University, Ministry of Health of the Russian Federation, \\ Nizhny Novgorod, 603005 Russia \\ *e-mail:mulnir@yandex.ru
}

Received August 30, 2021; revised August 30, 2021; accepted August 30, 2021

DOI: $10.1134 / \mathrm{S} 1811238221330018$

The article "Modern Porous Polymer Implants: Synthesis, Properties, and Application," written by R. S. Kovylin, D. Ya. Aleynik, and I. L. Fedushkin, was originally published electronically in SpringerLink on 30 June 2021 without Open Access. After publication in volume 63, issue 1, pages 29-46 the authors decided to make the article an Open Access publication. Therefore, the copyright of the article has been changed to (C) The Author(s), 2021 and the article is forthwith distributed under the terms of a Creative
Commons Attribution 4.0 International License (http://creativecommons.org/licenses/by/4.0/, CC BY), which permits use, duplication, adaptation, distribution and reproduction of a work in any medium or format, as long as you cite the original author(s) and publication source, provide a link to the Creative Commons license, and indicate if changes were made.

The original article can be found online at https://doi.org/10.1134/S1811238221010033 